\title{
Hookah smoking among young people in Bamako
}

\author{
Abdourahamane Diara ${ }^{1,2, *}$, Tidiane Diallo, ${ }^{1,3}$, Cheick Abou Coulibaly ${ }^{4}$, Sanou Khô Coulibaly ${ }^{4}$, Abdoul Karim Coulibaly ${ }^{1}$, \\ Hinde $\mathrm{Hami}^{5}$, Abdelmajid Soulaymani ${ }^{5}$, and Ababacar Maïga ${ }^{1,2}$ \\ ${ }^{1}$ Faculty of Pharmacy, University of Sciences, Techniques and Technologies, Bamako, Mali \\ ${ }^{2}$ National Institute of Public Health, Bamako, Mali \\ ${ }^{3}$ National Laboratory of Health, Bamako, Mali \\ ${ }^{4}$ Faculty of Medicine and Odonto-Stomatology, University of Sciences, Techniques and Technologies, Bamako, Mali \\ ${ }^{5}$ Laboratory of Biology and Health, Faculty of Science, Ibn Tofail University, Kenitra, Morocco
}

\begin{abstract}
Introduction: In Mali, shisha has become the most common form of tobacco consumption, which is not without danger for the consumer health. The aim of this study was to assess the consumption level of shisha among young people in the District of Bamako. Methods: This was a prospective study from March 2019 to March 2020. A total of 200 young shisha smokers aged 40 or under were included in this study. Results: The male sex was predominant, with $75 \%$ of cases. The majority, or $81.5 \%$, were under the age of 25 . According to study data, $26 \%$ of respondents said they smoke shisha at least once a day. Over a quarter of cases reported concurrent use of two or more addictive substances. The most common association was with alcohol $(13 \%)$, cannabis $(9 \%)$ and cocaine $(4.5 \%)$. According to the results, $69 \%$ of respondents thought that shisha is less harmful than cigarettes. Conclusion: Consumption of shisha has grown considerably in Mali in recent years. This study has highlighted a new form of multiple drug addiction, which could be harmful to the health of consumers. Thus, the authorities concerned must take appropriate measures to combat this scourge.
\end{abstract}

Keywords: Shisha; Polytoxicomania; Young people; Bamako

\footnotetext{
${ }^{*}$ Corresponding author: diarradocteur@yahoo.fr
} 


\section{Introduction}

The shisha is a waterpipe for smoking tobacco. This mode of consumption gives the feeling of being able to smoke in complete safety; however, as the World Health Organization (WHO) report states: waterpipe smokers and exposed persons suffer the same lung diseases, cardiovascular diseases and cancers as cigarette smokers [1]. Specifically, the harmful effects of Chicha have been rarely studied, unlike those of tobacco (cigarettes).

According to WHO estimates, the use of shisha affects more than 100 million people around the world daily [2]. In the past decade, Western countries have moved from marginal consumption to standard practice [3]. This consumption mainly concerns a young population (15-20 years) mainly attracted by the appeal of novelty, the conviviality and the flavored taste provided by shisha tobacco [4].

A survey conducted in Paris in 2007 showed that 50\% of 16-year-olds have already smoked shisha at least once, and $70 \%$ at the age of 18 years $[5,6]$. Another study conducted as part of the European campaign among 55,000 Europeans, showed that the average age of consumers of shisha (22.1 years) was younger than that of any other tobacco product (32.5 years for cigarettes, 46 years for cigars) and cannabis (23.7 years) [7].

With regard to the toxicity of shisha, the content of shisha smoke in particular in beryllium, chromium, cobalt, lead and nickel is higher than that of cigarette smoke [8-10].

In Mali, specifically in Bamako, there have been studies on smoking in bars, universities, high schools and the general population. In 2003, a study carried out by Haidara, revealed that on a sample of 5,433 subjects recruited in Bamako city, 27.89\% were smokers with a frequency of $2.6 \%$ of women $[11,12]$.

Shisha, a recent method of tobacco smoking in Bamako, with yet more dangerous effects, unfortunately little known due to scarcity of data on the effects of shisha on consumer health.

Thus, it seemed important to carry out this study on the consumption of shisha among young people in the District of Bamako in order to draw attention of young people and authorities to the harmful consequences of consuming shisha.

\section{Methodes}

\section{Type and location of the study}

This was a descriptive cross-sectional study carried out in commune VI of the District of Bamako, on the consumption of shisha. The study was carried out over a period of one year, from March 2019 to March 2020.

\section{Sampling}

We randomly selected 200 young shisha smokers between the ages of 14 and 40 .
To collect the data, we used a survey sheet which had taken into account, among other variables: age, sex, profession, frequency of consumption, level of knowledge about the risks associated with consumption of shisha, signs and symptoms observed by consumers. The data were analyzed by the statistical software EpiInfo7.

\section{Ethical considerations}

Free and voluntary participation of the participants was ensured after informed consent. Confidentiality and anonymity were respected during all phases of our study.

\section{Results}

Of the 200 young people surveyed, the age group 1924 years was the most represented with $42 \%$ (Figure 1) in addition the male sex was in the majority, ie $75 \%$ of cases.

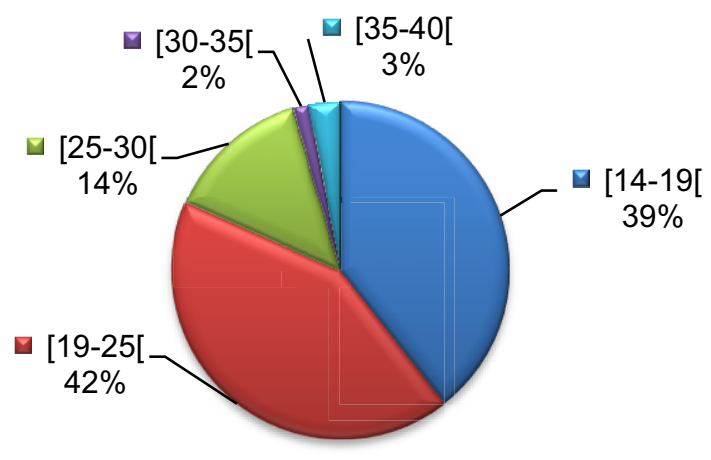

Fig. 1. Distribution of shisha consumers by age group

We noticed that the high school students were the most represented, ie $47.5 \%$ of cases and $53 \%$ had at least the first cycle studies certificate (BEPC). Regarding the frequency of consumption, we noticed that $26 \%$ of young people smoked shisha at least twice a week (Table I). 
Table I. Distribution of shisha consumers according to the frequency of consumption

\begin{tabular}{llr}
\hline Shisha use & $\begin{array}{l}\text { Frequency of } \\
\text { consumption }\end{array}$ & $\begin{array}{r}\text { Number of } \\
\text { consumers (\%) }\end{array}$ \\
\hline \multirow{2}{*}{ Daily } & 1 time & $52(26.0)$ \\
& 2 times & $33(16.5)$ \\
Weekly & 3 times & $18(9.0)$ \\
\cline { 2 - 3 } & 1 time & $4(2.0)$ \\
Monthly & 2 times & $52(26.0)$ \\
\hline Total & 1 time & $41(20.5)$ \\
\hline
\end{tabular}

Our results showed that $76 \%$ of the young people surveyed consumed it in grin (meeting place for young people) against $15 \%$ in hookah clubs (place where young people met regularly to smoke).

We found a high percentage of polydrug use $(63.5 \%$ of young surveyed).
Thus, $45.5 \%$ of the young people surveyed smoked cigarettes and/or consumed cocaine in addition to shisha. According to our results, the young people surveyed used fruit juice (16.5\%) and alcohol (13\%) in the hookah tank instead of water (Table II).

Table II. Distribution of shisha consumers according to their consumption patterns

\begin{tabular}{llrr}
\hline Mode of consumption & & $\begin{array}{r}\text { Number of } \\
\text { consumers }\end{array}$ & Prevalence \\
\hline \multirow{3}{*}{ Products used instead of water } & Fruit juice & 33 & 16.5 \\
& Alcohol & 26 & 13.0 \\
Products used instead of tabamel & Milk & 2 & 1.0 \\
\cline { 2 - 4 } & Cannabis leaves & 9 & 4.5 \\
Other addictive substances consumed in & Cigarette & 5 & 2.5 \\
\cline { 2 - 4 } addition to Chicha & Cigarette & 91 & 45.5 \\
& Cannabis & 27 & 13.5 \\
& Cocaine & 9 & 4.5 \\
\hline
\end{tabular}

This table shows the polydrug use patterns of the respondents.

We found that $53.5 \%$ of respondents knew that shisha is harmful to health. Indeed, according to the statements of consumers of shisha, the most frequent signs were cough $(58 \%)$, cold $(28 \%)$, and respiratory distress (13\%) (Figure 2).

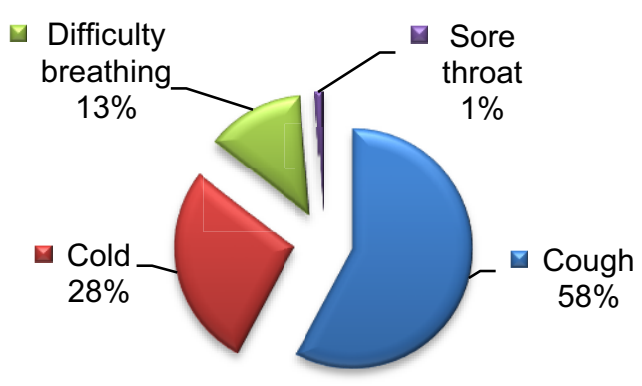

Fig. 2. Distribution of presented signs by shisha consumers
Our results showed that $69 \%$ of the young people surveyed thought that cigarettes were dangerous than shisha.

\section{Discussion}

The age group [19-25[ years was the most represented with $42 \%$ of cases. This could be explained by the passage from adolescence to adulthood which manifests itself in experiencing new adventures.

The male sex was the most represented with $75 \%$, this result is close to that of Rolif (2013) who found 69.9\% [13].

Students represented $47.5 \%$ of the respondents. In fact, hookah clubs, grin and especially nightclubs have always been the preferred sites for young people of school age.

In our study, we found that $53 \%$ of the young people surveyed had at least the BEPC, this result is close to that of Bah (2012) who found $60.8 \%$ [14]. This could be explained by the lack of awareness of the harmful 
effects of shisha on health and/or insufficient awareness in schools.

Our study showed that $76 \%$ of the young people surveyed consumed chicha in grin, the preferred meeting place for young people. Among these young people, $4.5 \%$ associated tabamel with cannabis, only $2.5 \%$ associated it with powdered tobbaco which could make the smoke even more toxic.

We found that consumers used fruit juice (16.5\%) or alcohol (13.5\%) instead of water. These practices could be sources of respiratory burns and other pathologies for these consumers.

Our study found that in addition to shisha, $45 \%$ of young people smoked cigarettes, $13.5 \%$ cannabis and $4.5 \%$ cocaine. This notion of multiple drug addiction could favor the occurrence of respiratory pathologies in this segment of the population.

However, the studies reviewed have shown that smoking shisha strongly increases the risk of lung cancer, lip cancer, bladder cancer and upper aerodigestive tract cancers [15].

In our study, $58 \%$ had a cough, this result is higher than that of Rolif (2013) who found 47\% [13].

Many young people still seemed to be informed about the harmful effects of shisha, so in our study, 53.5\% knew that shisha has harmful effects on their health, this result is lower than that of Bah (2012) who found $81.8 \%$ [14]. Regarding the toxicity of shisha, $69 \%$ of consumers believed that cigarettes were more harmful than shisha. This result is contrary to that of Bouquet (2019) who found that $51.2 \%$ of consumers thought that shisha was more harmful than cigarettes [16].

\section{Conclusion}

Waterpipe tobacco smoking is a form of tobacco consumption, which mainly concerns adolescents and young adults. This is proving to be compromising for the health of young people of school age. We observed a heavy consumption of shisha, a quarter of our respondents declared having smoked at least once a day. In addition, it appears in this study that consumers of shisha used other addictive substances (Cannabis, Cocaine).

Thus, the competent authorities must take appropriate measures to eradicate this scourge of polydrug addiction, to minimize its disastrous consequences for young people.

\section{References}

1. WHO Study Group on Tobacco Product Regulation, Advisory Note: waterpipe tobacco smoking: health effects, research needs and recommended actions by regulators, $11 \mathrm{p}$ (2005)

2. T. Asfar, K.D. Ward, T. Eissenberg, W. Maziak, BMC Public Health, 5, 1-9 (2005)

3. W. Maziak, K.D. Ward, R.A. Afifi Soweid, T. Eissenberg, Tob. Control, 13, 327-333 (2004)

4. Institut National du Cancer. La Chicha et risques pour la santé in www.e-cancer.fr

5. D. Chayet, À Paris, le tabagisme au collège et au lycée a repris in https://sante.lefigaro.fr/actualite/2010/05/05/10204 -paris-tabagisme-college-lycee-repris

6. B. Dautzenberg, J.F. Bertholon, M.-H. Becquemin MH, Y. Lettiero, C. Penfornis, Survey on the consumption pattern of hookah in 2007 in France. BEH, 21, 183-185 (2007)

7. B. Dautzenberg, J.Y. Nau, Tout ce que vous ne savez pas sur la chicha (Margaux Orange Ed./OFT, Paris, 144p 2007)

8. A. Shihadeh, R. Saleh, Food Chem. Toxicol., 43, 655-661 (2005)

9. A. Shihadeh, Food Chem. Toxicol., 41, 143-152 (2003)

10. A.J. Sasco, Tobacco Free Health, 164, 9-13 (2007)

11. M. Haidara, Le tabac et les intoxications des fumeurs : propositions et moyens de lutte contre le tabagisme au Mali (Thesis in Pharmacy, 1981)

12. A.G. Ndichout, Femmes et tabagisme dans les bars/restaurants et discothèques du District de Bamako (Thesis in Medicine, 2011)

13. A.K. Rolif, Tabagisme en milieu universitaire Bamakois (Thesis in Medicine, 2013)

14. M. Bah, Tabagisme dans les lycées de la commune $V I$ du district de Bamako (Thesis in Medicine, 2013)

15. J.J. Prignot, A.J. Sasco, E. Poulet, P.C. Gupta, T.Y. Aditama, Int. J. Tuberc Lung Dis., 12, 718-727 (2008)

16. L. Bouquet, Prévalence et facteurs associés à la consommation de narguilé : une enquête anonyme par questionnaire chez des lycéens havrais. État des connaissances actuelles sur les risques sanitaires encourus (Thesis in Medecine, 2019) 